\title{
VISUAL AND AUDITORY ANOMALIES IN CHEDIAK-HIGASHI SYNDROME ${ }^{1}$
}

\author{
DONNELL CREEL ${ }^{2}$, LAURENCE A. BOXER * and ANTHONY S. FAUCI ** \\ Veterans Administration Medical Center, and Department of Ophthalmology, University of Utah, Salt Lake City, Utah 84148, \\ * Department of Pediatric Hematology, School of Medicine, University of Michigan, Ann Arbor, Mich. 48109. and ** National Institute of \\ Allergy and Infectious Diseases, National Institutes of Health, Bethesda, Md. 20205 (U.S.A.)
}

(Accepted for publication: October 19, 1982)

The Chediak-Higashi syndrome (CHS) is a rare form of partial albinism which was initially recognized as a disorder of leukocyte morphology in which neutrophils, monocytes and lymphocytes contained giant cytoplasmic granules (Chediak 1952; Higashi 1954). The syndrome is further characterized by increased susceptibility to infection (Blume and Wolff 1972; Boxer and Stossel 1982) along with prolonged bleeding times resulting from impaired platelet function (Buchanan and Handin 1976; Boxer et al. 1977). Apparent hypopigmentation is the result of the aggregation of abnormally large melanosomes (Witkop et al. 1978). Their hair is an unusual metallic, frosted gray color. Ocular anomalies include pale irises, albinotic fundi, moderate photophobia and forms of nystagmus and strabismus. If they survive the recurrent infections of childhood, a progressive neuropathy frequently develops manifested by cranial and peripheral polyneuropathy, muscle weakness, foot drop, decreased muscle stretch reflexes and often ataxia (Kritzler et al., 1964; Lockman et al. 1967).

Since CHS is considered a form of oculocutaneous albinism it is reasonable to assume that CHS may include auditory and visual anomalies that appear in conjunction with ocular and oc-

\footnotetext{
${ }^{1}$ Research supported by the Veterans Administration and Grant AI 16984 from the NIH and a grant from the James Whitcomb Riley Memorial Foundation. This work was done during the tenure of Dr. Boxer as an Established Investigator of the American Heart Association.

${ }^{2}$ Reprint requests to D. Creel, Neuropsychology Research 151A, VA Medical Center, Salt Lake City, Utah 84148, U.S.A.
}

ulocutaneous albinism. Anatomical and electrophysiological studies have shown that mammals with congenital retinal hypopigmentation manifest chiasmal misrouting of optic fibers. Studies of albino mammals from mouse to humans have found that retinal ganglion fibers originating from approximately the first $25^{\circ}$ of temporal retina erroneously decussate at the optic chiasm and terminate in visual centers of the contralateral hemisphere (e.g., Guillery 1974; LaVail et al. 1978; Cooper and Blasdel 1980; Dräger and Olsen 1980). Chiasmic misrouting results in disruption of laminae of the dorsal lateral geniculate nucleus and subsequent anomalous geniculostriate projections. In human albinos monocular evoked potentials recorded from each hemisphere of occipital scalp reflect a definite hemispheric asymmetry as compared to the more symmetrical responses recorded from normally pigmented subjects (Creel et al. 1974, 1978, 1981; Taylor 1978; Coleman et al. 1979). There is also evidence from scalp-recorded auditory brain stem responses (ABRs) that there may be a similar misrouting of decussating auditory pathways in albinos (Creel et al. 1980, 1983).

Humans with CHS are relatively well-pigmented for being a form of oculocutaneous albinism but manifest the probable prerequisite for having at least some misrouting of visual fibers. In addition to hypopigmentation, humans that demonstrate optic misrouting have nystagmus and strabismus as a group and lack stereovision (Taylor 1978; Creel et al. 1981). Patients with CHS usually have nystagmus or strabismus, and their stereovision can be easily tested. There is also evidence from anatomical studies of the Aleutian mink 
(Sanderson et al. 1974; Guillery et al. 1979), beige mouse (LaVail et al. 1978) and CHS cat (Creel et al. 1982) which have diseases considered analogous to CHS in humans, that the organization of their dorsal lateral geniculate is abnormal indicative of misrouted retinogeniculate fibers.

\section{Subjects}

Four patients with CHS were tested. Two were brothers aged 30 and 31 and two were unrelated 6-year-old girls (Boxer et al. 1979). All four fulfilled the criteria for CHS (Blume and Wolff 1972). Both males exhibited peripheral neuropathy with limb hypotonia and one had bilateral foot drop requiring bracing. One male had severe hypotonia of the esophagus with esophago-gastric reflux requiring surgery. It is suspected that he also has gastrointestinal neuropathy of the lower gut similar to the diabetic type since he has frequent diarrhea and poor sphincter tone and control. The EEG of both adult males demonstrated diffuse slowing of background activity. There were, however, no focal or epileptiform abnormalities or evidence of lateralized pathology. There were no apparent neurological deficits in the two girls except for ophthalmological symptoms. One girl demonstrated a mild strabismus and the other moderate nystagmus. Both males and the girl with nystagmus failed the Titmus stereovision test indicating lack of binocular stereovision. The girl with strabismus performed normally when tested for stereovision.

\section{Methods}

Optic misrouting associated with hypopigmentation can be detected by comparing VEPs elicited by binocular and monocular stimulation while recording from left and right occipital scalp. Evidence of optic misrouting can be detected by visual examination of the VEPs. Statistical analysis is not necessary.

The most efficient stimulus for detecting misrouted optic fibers is pattern onset (Creel et al. 1981). Stimuli were presented on a TV monitor $1 \mathrm{~m}$ from the subject. The TV screen subtended $20^{\circ}$ of visual field. A computer controlled display of $50^{\prime}$ checks of maximum contrast that appeared for $500 \mathrm{msec}$ and disappeared to a neutral gray of equal total luminance for $500 \mathrm{msec}$. One hundred responses to pattern onset were averaged for binocular and monocular conditions. The bandwidth of the EEG amplifiers was $1-100 \mathrm{~Hz}( \pm 3 \mathrm{~dB})$.

By analogy with the model of the visual system, significant alteration in decussation of auditory pathways should be reflected in the comparison of the ABRs recorded from each hemisphere after monaural stimulation. It has been reported that an ABR recorded from the electrode configuration of vertex referred to the ear ipsilateral to monaural stimulation $\left(\mathrm{Cz}-\mathrm{A}_{\mathrm{i}}\right)$, compared to the $\mathrm{ABR}$ recorded between the vertex and the ear contralateral to stimulation $\left(\mathrm{Cz}-\mathrm{A}_{\mathrm{c}}\right)$ correctly lateralizes pathology in the brain stem (Oh et al. 1981). Rarefaction clicks of $100 \mu \mathrm{sec}$ duration and an intensity of $70 \mathrm{~dB}$ HL were presented monaurally through TDH-39 earphones at a rate of $11.3 / \mathrm{sec}$. Potentials evoked by 2000 clicks were averaged; the period of analysis was $10 \mathrm{msec}$ from the onset of each click. The bandpass setting was $150-3000$ $\mathrm{Hz}( \pm 3 \mathrm{~dB})$.

The participants had normal hearing. Subjects were seated in a padded chair in a darkened, sound-deadened and electrically shielded room. Disc electrodes were attached according to the 10-20 system. For recording VEPs scalp electrode locations $\mathrm{O} 1$ and $\mathrm{O} 2$ were referred to linked ears $(\mathrm{A} 1+\mathrm{A} 2)$, with $\mathrm{Cz}$ being used for ground. $\mathrm{ABRs}$ were recorded from $C z$ referred to the ipsilateral ear $\left(A_{i}\right)$ and contralateral ear $\left(A_{c}\right)$. Resistances were equal and below $3000 \Omega$.

\section{Results}

The VEPs evoked by onset stimuli were normal in form and hemispheric symmetry following binocular stimulation. However, all 3 CHS individuals that failed the stereovision test demonstrated abnormal VEPs following monocular stimulation. Monocular stimulation of either eye produced a significant attenuation of components in the first $125 \mathrm{msec}$ of the VEP recorded from the hemisphere ipsilateral to the stimulated eye (Fig. 1). 


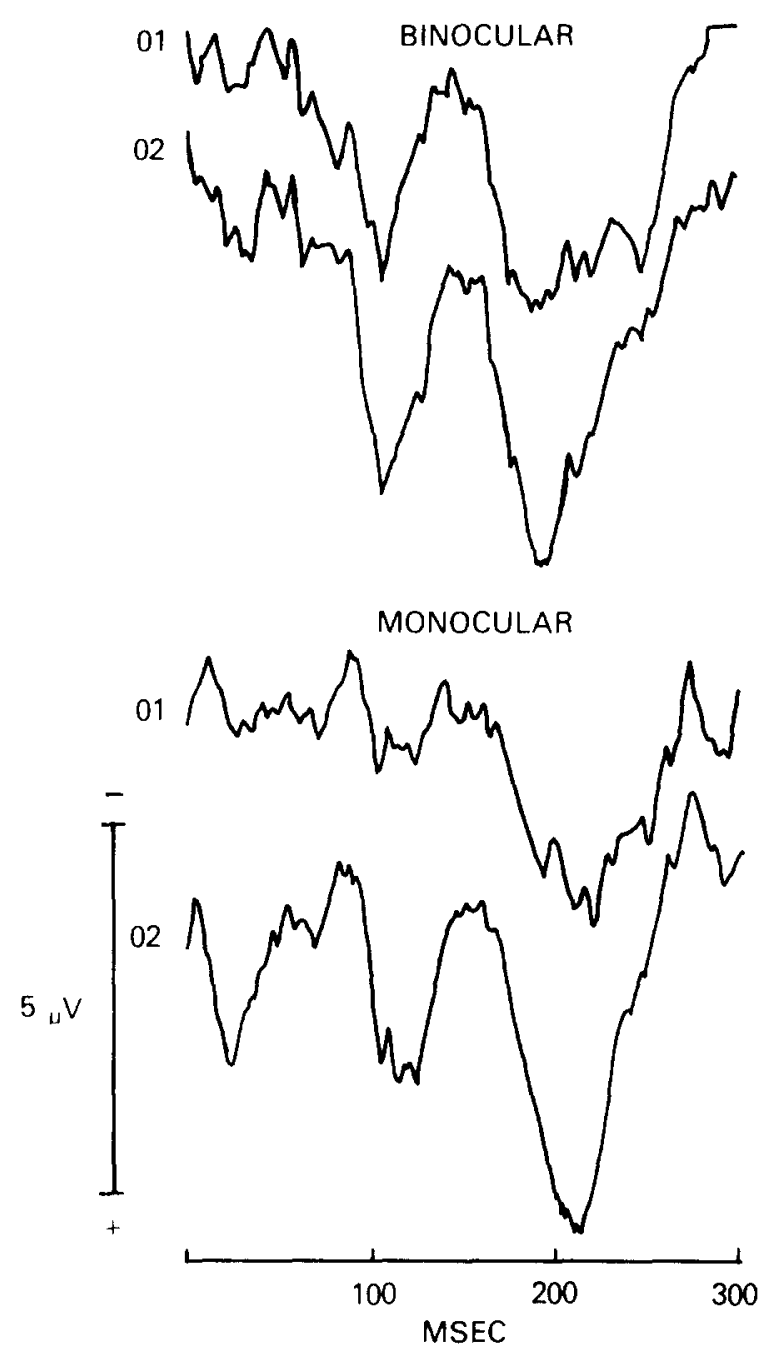

Fig. 1. Binocular and monocular visually evoked potentials to pattern onset stimulation recorded from each hemisphere of a human with CHS. Monocular stimulation of the left eye resulted in an attenuation of the response recorded from the ipsilateral hemisphere $(\mathrm{Ol})$.

The ipsilateral ABRs $\left(\mathrm{Cz}-\mathrm{A}_{\mathrm{i}}\right)$ of all $4 \mathrm{CHS}$ subjects were normal in form and peak latencies. The amplitude of components of ABRs recorded from all 4 CHS subjects was approximately onehalf the amplitude of components of normally pigmented subjects. Also, contralateral ABR $(\mathrm{Cz}-$ $A_{\text {. }}$ ) positive components peaking between 3 and 5 msec were significantly attenuated or completely
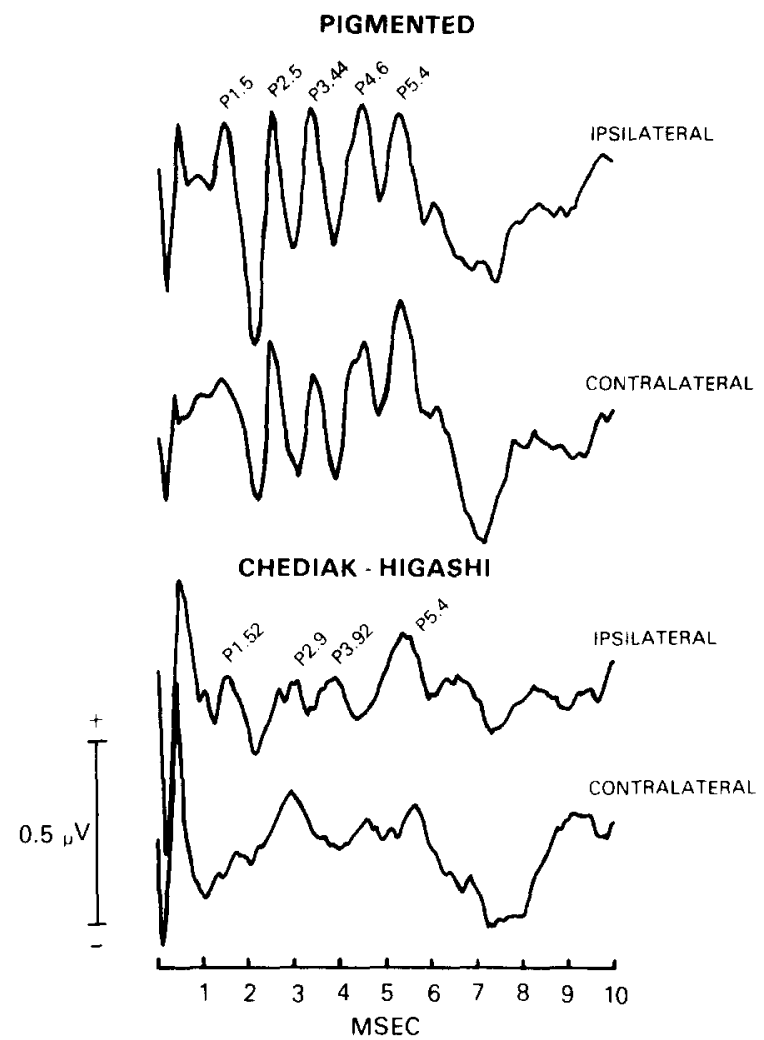

Fig. 2. Representative ABRs recorded from a pigmented human and a person with $\mathrm{CHS}$. ABRs recorded from reference points in the hemisphere ipsilateral $\left(\mathrm{Cz}-\mathrm{A}_{\mathrm{i}}\right)$ and contralateral $\left(\mathrm{Cz}-\mathrm{A}_{\mathrm{c}}\right)$ to the stimulated ear indicate significant hemispheric asymmetry in the response recorded from individuals with CHS. The peak latencies of the positive components in the ipsilateral response are indicated.

reversed in polarity and prolonged in latency (Fig. 2).

\section{Discussion}

In hypopigmented individuals, such as oculocutaneous or ocular albinos, the VEPs following monocular stimulation are quite different when hemispheres are compared. Monocular stimulation most often produces a change of polarity or attenuation of early VEP components recorded from the occiput ipsilateral to the eye stimulated (Taylor 1978; Coleman et al. 1979; Creel et al. 1981). Monocular VEPs of the 3 CHS subjects that failed 
the stereovision test resembled abnormal VEPs of traditional forms of oculocutaneous albinism. The hemispheric asymmetry of monocular VEPs of these CHS subjects, along with the anatomical evidence from studies of mink (Sanderson et al. 1974: Guillery et al. 1979), mice (LaVail et al. 1978) and cats (Creel et al. 1982) with CHS provide substantial evidence that most humans with CHS probably have misrouted retino-geniculostriate projections. The failure to perform the stereovision test is further confirmation that misrouting of optic neurons has disturbed the anatomical substrate underlying binocular vision at the cortical level. The observation that one subject with CHS had normal monocular VEPs and also performed normally on the stereovision test indicates probable variable expression of visual anomalies in humans with CHS.

Previous studies of $\mathrm{ABRs}$ recorded from electrodes ipsilateral $\left(\mathrm{Cz}-\mathrm{A}_{i}\right)$ and contralateral $\left(\mathrm{Cz}_{\mathrm{z}} \mathrm{A}_{\mathrm{c}}\right)$ to monaural stimulation in human albinos indicate an asymmetry of ABRs with positive components peaking between 3 and $5 \mathrm{msec}$ in the contralateral ABR being significantly attenuated in amplitude (Creel et al. 1980). Similar differences have been reported for albino cats (Creel et al. 1983). The complex spatial and temporal relationship of neuronal generators of early components of ABRs precludes any simple 1:1 relationship between a given anatomical site and a particular component of the $\mathrm{ABR}$. However, there is general agreement concerning the principal generators of components that appear in the first 5 msec (e.g., Stockard and Rossiter 1977: Achor and Starr 1980a, b; Buchwald et al. 1981: Hashimoto et al. 1981). In all studies of both albino humans and cats the components that are attenuated in amplitude or missing from the contralateral ABR are those components most often associated with neuronal sites at the level of the initial decussation of auditory fibers, i.e., the superior olivary nuclei and trapezoid body. Results from studies of ABRs of both albino humans (Creel et al. 1980) and cats (Creel et al. 1983) and the present data from humans with CHS suggest anomalies in brain stem auditory structures involved in transmitting information to the contralateral hemisphere, most likely via the acoustic striae, trapezoid body and superior olivary nuclei.
It is unlikely that anomalies in the central auditory system are truly analogous to misrouting in the visual system. More likely, the paucity of pigment in the inner ear may be related to a neuronal cascade of changes which affects the cochlear nuclei and acoustic striae. The smaller amplitude ABR recorded from albino cats and the subjects with CHS in this study may be due to fewer or smaller diameter axons in their peripheral and/or central auditory system. Since the older individuals with CHS manifest polyneuropathies, these multiple neural degenerations may contribute to their sensory anomalies.

Until this study the Chediak-Higashi syndrome was not known to include central sensory deficits. However, CHS is generally classified as a form of oculocutaneous albinism and visual anomalies have been described in the traditional forms of oculocutaneous albinism (see Taylor 1978; Witkop et al. 1978 for reviews). Anomalies of the central auditory system also appear to exist in oculocutaneous albinism (e.g.. Henry and Haythorn 1975; Maxson 1979; Creel et al. 1980, 1983). Although the hair, skin and irises are relatively well pigmented in CHS, these individuals apparently have anomalies of their central visual and auditory pathways.

\section{Summary}

Albinism is correlated with misrouting of decussating retinal fibers in the brain. There is also evidence of anomalies of decussating auditory pathways in albinos. The Chediak-Higashi syndrome (CHS) is a rare form of partial albinism which includes increased susceptibility to infections, a hemorrhagic tendency and peripheral polyneuropathies. Binocular and monocular patternonset visually evoked potentials (VEPs) and monaural auditory brain stem responses (ABRs) were recorded from 4 subjects with CHS. Three of the CHS demonstrated asymmetric monocular VEPS and failed the Titmus stereovision test. All 4 CHS produced asymmetric ABRs similar to those reported for albinos. Although the hair. skin and irises are relatively well pigmented in CHS, these individuals apparently have anomalies of their central visual and auditory pathways. 


\section{Résumé}

\section{Anomalies visuelles et auditives dans le syndrome de Chediak-Higashi}

L'albinisme s'accompagne d'une perturbation de la décussation des fibres rétiniennes dans le cerveau. Il existe également des données concernant des anomalies de décussation des voies auditives chez l'albinos. Le syndrome de ChediakHigashi $(\mathrm{SCH})$ est une forme rare d'albinisme partiel qui s'accompagne d'une augmentation de la sensibilité aux infections, d'une tendance aux hémorragies et de polyneuropathies périphériques. Les potentiels évoqués visuels à l'apparition d'un pattern présenté soit en monoculaire, soit en binoculaire, ainsi que les réponses auditives monaurales du tronc cérébral ont été enregistrés chez 4 sujets $\mathrm{SCH}$. Trois des 4 patients ont présenté des PEV monoculaires asymétriques et n'ont pas réussi le test Titmus de Stéréovision. Les 4 sujets $\mathrm{SCH}$ ont développé des réponses auditives du tronc cérébral asymétriques identiques à celles déjà rapportées pour les albinos. Bien que les cheveux, la peau et l'iris soit relativement bien pigmentés chez les $\mathrm{SCH}$, ces sujets présentent apparemment des anomalies dans les trajets suivis par les voies centrales visuelles et auditives.

\section{References}

Achor, L.J. and Starr, A. Auditory brain stem responses in the cat. I. Intracranial and extracranial recordings. Electroenceph. clin. Neurophysiol., 1980a, 48: 154-173.

Achor, L.J. and Starr, A. Auditory brain stem responses in the cat. II. Effects of lesions. Electroenceph. clin. Neurophysiol., 1980b, 48: 174-190.

Blume, R.S. and Wolff, S.M. The Chediak-Higashi syndrome: studies in four patients and a review of the literature. Medicine (Baltimore), 1972, 51: 247-280.

Boxer, L.A. and Stossel, T.P. Granulocyte disorders: qualitative abnormalities of granulocytes. In: W. Williams, E. Beutler, A. Ersler and M. Lichtman (Eds.), Hematology, 3rd edn. McGraw-Hill, New York, 1982: in press.

Boxer, G.J., Holmsen, H., Robkin, L., Bang, N.U., Boxer, L.A and Baehner, R.L. Abnormal platelet function in Chediak Higashi syndrome. Brit. J. Haematol., 1977, 35: 521-533.

Buxer, L.A., Albertini, D.F., Oliver, J.M. and Baehner, R.L. Impaired microtubule assembly in Chediak-Higashi syndrome neutrophile correctable by ascorbic acid. Brit. J. Haematol., 1979, 43: 207-213.
Buchanan, G.R. and Handin, R.I. Platelet function in Chediak-Higashi syndrome. Blood, 1976, 47: 941-948.

Buchwald, J.S., Hinman, C., Norman, R.J., Huang, C.-M. and Brown, K.A. Middle- and long-latency auditory evoked responses recorded from the vertex of normal and chronically lesioned cats. Brain Res., 1981, 205: 91-109.

Chediak, M. Nouvelle anomalie leucocytaire de caractère constitutionnel familial. Rev. Hematol., 1952, 7: 362-367.

Coleman, J., Sydnor, C.F., Wolbarsht, M.L. and Bessler, M. Abnormal visual pathways in human albinos studied with visually evoked potentials. Exp. Neurol.. 1979. 65: 667-679.

Cooper, M.L. and Blasdel, G.G. Regional variation in the representation of visual field in the visual cortex of the Siamese cat. J. comp. Neurol., 1980, 193: 237-253.

Creel, D., Witkop, Jr., C.J. and King, R.A. Asymmetric visually evoked potentials in human albinos: evidence for visual system anomalies. Invest. Ophthal., 1974, 13:430-440.

Creel, D., O'Donnell, Jr., F.E. and Witkop, Jr., C.J. Visual system anomalies in human ocular albinos. Science, 1978, 201: $931-933$.

Creel, D., Garber, S.R., King, R.A. and Witkop, Jr., C.J. Auditory brainstem anomalies in human albinos. Science, 1980, 209: 1253-1255.

Creel, D., Spekreijse, H. and Reits, D. Evoked potentials in albinos: efficiency of pattern stimuli in detecting misrouted optic fibers. Electroenceph. clin. Neurophysiol.. 1981, 52: 595-603.

Creel, D., Collier, L.L., Leventhal, A.G., Conlee, J.W. and Prieur, D.J. Abnormal retinal projections in cats with the Chediak-Higashi syndrome. Invest. Ophthal. Vision Sci., 1982. 23: 798-800.

Creel, D., Conlee, J.W. and Parks. T.N. Auditory brainstem anomalies in albino cats. I. Evoked potential studies. Brain Res.. 1983, 260: 1-9.

Dräger, U.C. and Olsen, J.F. Origins of crossed and uncrossed retinal projections in pigmented and albino mice. J. comp. Neurol., 1980, 191: 383-412.

Guillery, R.W. Visual pathways in albinos. Scient. Amer., 1974. 230: $44-54$

Guillery, R.W., Oberdorfer, M.D. and Murphy, E.H. Abnormal retino-geniculate and geniculo-cortical pathways in several genetically distinct color phases of the mink (Mustela vison). J. comp. Neurol., 1979, 185: 623-656.

Hashimoto, I., Ishiyama, Y., Yoshimoto, T. and Nemoto, S. Brain-stem auditory-evoked potentials recorded directly from human brain-stem and thalamus. Brain, 1981, 104: $841-859$.

Henry, K. and Haythorn, M. Albinism and auditory function in the laboratory mouse. I. Effects of single-gene substitutions on auditory physiology, auditory seizures, and developmental processes. Behav, Genet., 1975, 5: 137-149.

Higashi, $O$. Congenital gigantism of peroxidase granules: first case ever reported of qualitative abnormality of peroxidase. Tohoku. J. exp. Med., 1954, 59: 315-332.

Kritzler, R.A., Terner, J.Y., Lindenbaum, J., Magidsen, J., Williams, R., Preisig, R. and Philips, G.B. Chediak-Higashi syndrome - cytologic and serum lipid observations in a case and family, Amer. J. Med., 1964, 36; 583-594. 
LaVail. J.H., Nixon, R.A. and Sidman, R.L. Genetic control of retinal ganglion cell projections. J. comp. Neurol., 1978, 182: $399-422$.

Lockman, L.A., Kennedy, W.R. and White, J.G. The ChediakHigashi syndrome: electrophysiologic and electron microscopic observations on the peripheral neuropathy. J. Pediat. 1967. 70: 942-951.

Maxson, S. Strain differences in lateralization of acoustic priming for susceptibility to audiogenic seizures. Exp. Neurol., 1979. 63: 436-443.

Oh, S.I., Kuba. T., Soyer, A., Choi, I.S., Bonikowski, F.P. and Vitek, J. Lateralization of brainstem lesions by brainstem auditory evoked potentials. Neurology (Minneap.), 1981 , 31: $14-18$.
Sanderson, K.E., Guillery, R.W. and Shackelford, R.M. Congenitally abnormal visual pathways in mink (Mustela vison) with reduced retinal pigment. J. comp. Neurol., 1974, 154: $225-248$.

Stockard, J.J. and Rossiter, V.S. Clinical and pathological correlates of brain stem auditory response anbormalities. Neurology (Minneap.), 1977, 27: 316-325.

Taylor, W.O.G. Visual disabilities of oculocutaneous albinism and their alleviation. Trans. Ophthal. Soc. U.K., 1978, 98: 423-445.

Witkop, Jr., C.J., Quevedo, Jr., W.C. and Fitzpatrick. T.B. Albinism. In: J. Stanbury, J. Wyngaarden and D. Frederickson (Eds.), The Metabolic Basis of Inherited Disease, 4th edn. McGraw-Hill, New York, 1978: 283-316. 